\title{
Editorial
}

\section{Catheter based treatment for all patients with acute coronary syndromes: is it possible for the UK NHS to cope with this problem?}

The pace of interventional cardiology is accelerating across Europe, although there is wide variation in provision. ${ }^{1}$ The enthusiasm for immediate or very early intervention in patients with acute ischaemic coronary syndromes places huge demands on health care services, demands that are likely to increase as the "urgency to intervene (in order to reperfuse)" philosophy spreads. What could be the implications for such a policy for the UK National Health Service?

Each year approximately 300000 patients suffer an acute myocardial infarction in the UK, of whom approximately 200000 reach hospital alive. The 28 day case fatality rate for these patients remains unacceptably high at between $20 \%$ and $25 \% .^{23}$ Over the past 25 years, registry data have shown a relatively stable admission rate for patients with acute myocardial infarction, but an enormous increase in patients with non-infarct ischaemic pain, a ratio of at least $5: 1 .{ }^{4}$ Of these, perhaps as many as $20 \%$ fulfill diagnostic criteria for unstable angina, giving a yearly admission rate in the UK of at least 200000 . If it were agreed that best practice for patients with acute myocardial infarction or unstable angina was immediate or very early transfer to an interventional centre, what expansion of current activity would be required?

British Cardiac Society records estimate that 315 NHS hospitals (adult and paediatric) in the UK are able to offer at least some cardiac facilities. Of these, 60 provide adult cardiac catheterisation services using either a dedicated, shared or mobile laboratory, and a further 36 provide the fully comprehensive investigative, invasive, and surgical services of an adult tertiary referral centre. In order not to contravene guidelines of the British Cardiac Society and Royal College of Physicians, any percutaneous transluminal coronary angioplasty (PTCA) should be done in an environment in which there is on-site surgical care or, if transfer were to be necessary, at a distance such that the journey time would be less than 30 minutes and time to bypass within 90 minutes. How much PTCA currently takes place in the UK?

The latest audit of the British Cardiovascular Intervention Society (1996) reports PTCA activity from 53 centres. $^{5}$ There were 20511 PTCA procedures performed, of which $3682(18 \%)$ were for unstable angina and 457 (2\%) for acute myocardial infarction, but not necessarily as a primary procedure. This amounts to 4139 procedures for patients with acute coronary syndromes. Accepting the date of the audit, what is the potential shortfall in acute activity?

If we assume that half of the 200000 patients admitted with acute myocardial infarction each year were eligible for thrombolysis and therefore likely to be eligible for primary intervention instead (the putative preferred option), the potential demand for acute PTCA would immediately exceed five times the current level of total PTCA activity. We also need to consider the $50 \%$ of patients deemed not eligible for thrombolysis; what proportion of these might be suitable for interventional treatment? Another daunting figure no doubt, but so far not quantified.

Next comes unstable angina with an estimated (and probably conservative) annual admission rate of 200000 . If only half of these patients were considered for angiography or interventional treatment, that still adds another huge potential demand for such activity.

It is clear, even using rounded estimates, that there is little opportunity for primary interventional treatment for the vast majority of patients admitted with acute ischaemic coronary syndromes in the UK at present. This is probably true for most of Europe, but the UK appears more disadvantaged than most western European countries, ranking 12th of 15 for coronary angiography (with 1429 procedures $/ 10^{6}$ inhabitants compared with $4667 / 10^{6}$ in Germany) and similarly for total PTCA (310/10 $v$ $1358 / 10^{6}$ in Germany). ${ }^{1}$ No doubt there are many reasons for these differences, especially the number of registered specialists in cardiology: the UK has about $10 / 10^{6}$ inhabitants, Germany twice that number, Sweden four times, and France eight times!

The current ill preparedness of the UK health service for a predominantly interventional approach for patients with either acute myocardial infarction or unstable angina pectoris should be cause for thought and reassessment, but not for shame. The rate of interventional activity in Europe and elsewhere far exceeds the supporting evidence. ${ }^{6}$ We should review such evidence critically, assess its general applicability, then decide whether we should deploy our interventional expertise more equitably and take a more liberal, but not cavalier, approach to its practice. Follow evidence not fashion!

Professor of Cardiovascular Medicine, University Hospital, $\mathrm{R}$ WILCOX Nottingham NG7 2UH, UK

1 Windecker S, Maier-Rudolph W, Bonzel T, et al, on behalf of the Working Group Coronary Circulation of the European Society of Cardiology. Interventional cardiology in Europe 1995. Eur Heart f 1999;20:484-95.

2 Tunstall-Pedoe H, Morrison C, Woodward M, et al. Sex differences in myocardial infarction and coronary deaths in the Scottish MONICA population of Glasgow 1985-1991. Presentation, diagnosis, treatment and 28-day case fatality of 3991 events in men and 1551 events in women. Circulation 1996;93:1981-92

3 Norris RM, for the UK Heart Attack Study Collaborators. Sudden cardiac death and acute myocardial infarction in three British health districts: the UK heart attack study. London: British Heart Foundation, 1999.

4 Brown N, Young T, Gray D, et al. Inpatient deaths from acute myocardial infarction, 1982-92: analysis of data in the Nottingham heart attack regisinfarction, 1982-92: analysis

5 Gray $\mathrm{HH}$, on behalf of the Council of the British Cardiovascular Interventional Society. Cardiac interventional procedures in the UK 1992 to 1996. Heart 1999;82 (suppl II):II10-17.

6 Vogt A, Neuhaus K-L. Thrombolysis and mechanical intervention following myocardial infarction. Eur Heart $\mathcal{f}$ 1996;17(suppl.E):49-54. 